\title{
Determinants of Virological Failure Among HIV-Infected Children on First-Line Antiretroviral Therapy in West Gojjam Zone, Amhara Region, Ethiopia
}

\author{
Awoke Shumetie' \\ Nurilign Abebe Moges $\mathbb{( D}^{2}$ \\ Muluken Teshome 2 \\ Getnet Gedif (iD) ${ }^{2}$ \\ 'Agut Antiretroviral Treatment Clinic, \\ Agut Health Center, Gish Abay, Amhara \\ Region, Ethiopia; ${ }^{2}$ Department of Public \\ Health, College of Health Sciences, \\ Debre Markos University, Debre Markos, \\ Amhara Region, Ethiopia
}

Background: Viral load monitoring is a golden indicator for diagnosing treatment failure in patients with HIV. HIV-infected children are considered a priority group for routine viral load monitoring. Globally, the World Health Organization recommends 95\% of HIV patients have viral suppression. Factors leading to virological failure are not well understood and studied. This study aimed to determine virological failure among HIV-infected children on first-line antiretroviral therapy in the West Gojjam Zone, Amhara region. Ethiopia.

Methods: An institutional-based unmatched case-control study was carried out from October 1 to October 15, 2020, among HIV-infected children on first-line antiretroviral therapy. The study included 94 cases and 276 controls, with a total sample size of 370 out of $378 \mathrm{HIV}$-infected children. A structured English version checklist was used to collect data through chart review. The data were entered using Epi-data 4.2 and exported into SPSS version 20 for analysis. Descriptive statistics were conducted to summarize the sample characteristics. Bivariate and multivariate analyses were used to describe each explanatory variable's association with the outcome variable. A bivariate analysis with a p-value $<0.25$ was selected for multivariate analysis. Adjusted odds ratio with $95 \%$ confidence intervals was conducted, and p-value $<0.05$ was considered statistically significant.

Results: Non-disclosure $(\mathrm{AOR}=4.26 ; 95 \% \mathrm{CI}: 2.09,8.70)$, baseline viral load $>1000$ copies $/ \mathrm{mL}(\mathrm{AOR}=10.82 ; 95 \% \mathrm{CI}: 5.4,21.67)$, recent poor adherence $(\mathrm{AOR}, 6.05,95 \%$ $\mathrm{CI}, 1.70,21.55)$ and missed clinical appointments (AOR $=8.03 ; 95 \% \mathrm{CI}: 3.88,16.65)$ were factors independently associated with virological failure.

Conclusion: Disclosure of HIV status of patients early, according to their age and adherence to counseling, should be emphasized. Efforts should be strengthened to trace back for missed clinical appointments and strictly follow-up with antiretroviral (ARV) medication for a baseline viral load $>1000$ copies $/ \mathrm{mL}$ that helps to boost immunity and suppress viral replication.

Keywords: HIV/AIDS, ART, case-control, virological failure, children, Amhara region, Ethiopia

\section{Introduction}

AIDS continues to be a major global health priority, where 37.7 million people were living with HIV, of whom 1.7 million were children (age $<15$ years) in 2020 . ${ }^{1}$ Eastern and Southern Africa remain the region most heavily affected, accounting for approximately $55 \%$ of all people and two-thirds of all children living with Human Immunodeficiency Virus (HIV). ${ }^{2}$ Globally, AIDS remains the leading cause
Correspondence: Getnet Gedif P.O.Box: +251269

Tel +25I-9l8-06-66-03

Email get4ged@gmail.com;

getnet_gedif@dmu.edu.et 
of mortality with 680,000 people of whom children accounted for 99,000 deaths in 2020. ${ }^{3}$ By the year 2020, the United Nations Program on HIV/AIDS (UNAIDS) revised and declared the three 95s', "95-95-95" call where $95 \%$ of people within the subpopulation who are living with HIV know their HIV status, of who $95 \%$ people access Antiretroviral therapy (ART), and 95\% people, whom are on treatment are suppressed viral load. ${ }^{4}$ Ethiopia adopted the new three 95's targets and expanded the program to many viral load test sites to implement the third $95 .^{5}$

Tracking progress towards 90-90-90 targets, UNAIDS reported that, of all people living with HIV worldwide, $73 \%$ were accessing ART and $66 \%$ were virally suppressed. ${ }^{1}$ Approximately 44,000 children are living with HIV and 2800 are newly infected annually in Ethiopia by $2020 .^{6}$ According to Ethiopian Demographic Health Survey (EDHS) 2016, 3800 children aged 0-14 were newly infected with HIV and 53\% had viral suppression coverage. ${ }^{7}$

Virological failure is a treatment failure (clinical and immunological) and is defined as a plasma viral load above 1000 copies $/ \mathrm{mL}$ based on two consecutive viral load measurements after 3-months of adherence support and taking ART for at least 6 months. Viral load monitoring can be carried out at 6 months, at 12 months, and then every 12 months thereafter if the patient is stable on ART. If treatment failure is suspected and the first viral load result is $>1000$ copies $/ \mathrm{mL}$, a viral load test can also be carried out. ${ }^{8}$ Viral load is the number of HIV copies in the body. Viral load test indicates the progression of HIV in the body and is the golden approach for evaluation and monitoring of ART responses. A high viral load may indicate a recent HIV transmission or HIV that is untreated or uncontrolled. The WHO recommends viral load monitoring to ensure viral load suppression is achieved and maintained, but large gaps in global access remain particularly in low- and middle-income countries due to limited laboratory facilities and trained personnel. ${ }^{9}$ Antiretroviral therapy (ART) refers to any HIV treatment that uses a combination of two or more drugs. The goal of ART is to suppress HIV replication to a level below which drug resistance mutation does not emerge. It prevents HIVrelated morbidity and mortality by increasing the number of immune cells while also decreasing the number of HIV virus present in the body. ${ }^{8}$ ART is recommended for all people with HIV as soon as possible after diagnosis without any restriction of $\mathrm{CD} 4$ count, this is essential for children because of the transition from infancy to adulthood. ${ }^{8}$ However, due to drug resistance mutation, the effectiveness of the ART is decreased, and viral suppression failure can happen. ${ }^{10}$ Viral suppression enhances the body's immune system and prevents the transmission of HIV to other people. Keeping regular viral suppression is critical for all HIV-infected patients, especially for children who require life-long ART. HIV-infected children are considered as a priority group for routine viral load monitoring. ${ }^{11}$

Studies show that virological failure occurs due to factors, such as being male in gender, ${ }^{12-15}$ age $<3$ years, ${ }^{16-18}$ being orphaned, ${ }^{14,15}$ non-disclosure, ${ }^{15,19}$ poor adherence, ${ }^{15,17,20,21}$ has not being on ART for a long period $^{13}$ and take ART suboptimal. ${ }^{12}$ In addition, opportunistic infections, ${ }^{15-17,19,20,22,23}$ malnutrition, ${ }^{14,16}$ were WHO stage 3 and $4,{ }^{15,24}$ lower CD4 count (Cells/ $\mathrm{mL}),{ }^{12,15,16,20,24-26}$ initial viral load $>1000$ copies/ $\mathrm{mL},{ }^{21,27} \mathrm{D} 4 \mathrm{~T} / 3 \mathrm{TC} / \mathrm{NVP}$ based regimen, ${ }^{21,22,28-30}$ regimen change, ${ }^{14,15}$ longer duration on ART, ${ }^{15,31}$ treatment interruption, ${ }^{12,13,32}$ treatment failure due to drug resistance. High viral load leads to low CD4 cell count, increasing the risk of illnesses such as severe infections and some cancers.

Viral load monitoring is important to early identify treatment failure, provide adherence counseling, and prevent unnecessary switching of children to second-line treatment or delay to switching of children to second-line treatment. The occurrence of treatment failure leads to the need for more expensive and less-tolerable second-line drugs. Sustaining a low viral load is important for children with the progression of AIDS and associated coinfections. ${ }^{8}$ There have been few studies on the determinants of virological failure among children in Ethiopia. Therefore, this study aimed to identify determinants of virological failure among HIV-infected children on firstline antiretroviral therapy in the West Gojjam Zone, Amhara region, Northwest Ethiopia.

\section{Methods and Materials Study Design, Setting and Period}

An institutional-based unmatched 3:1 case-control study design was employed to assess virological failure and its determinants from October 1 to 15, 2020 at public health facilities in the West Gojjam Zone, which is found in Amhara region, northwest Ethiopia. Finote-Selam town is the capital of the Zone and is located $176 \mathrm{~km}$ from Bahir 
Dar, the capital of Amhara national regional state. Based on the 2014 Ethiopian fiscal year (EFY) of Ethiopia (MO FED), this Zone had a total population of 2,795,775 of whom 1,395,091 were men and 1,400,684 women. Of this, the children account for about 1,193,656. At the time of data collection, 104 health centers, 6 primary hospitals, and 1 General Hospital were in the West Gojjam Zone. Of these, all hospitals and 48 health centers provide ART services, and more than 143,225 patients are on ART that account for $69 \%$ out of PLHIV in the region. According to the 2013 EFY 8 months report of the Amhara region $(22,191,890$ total population, above 9,461,290 are children), among 208,001 people living with HIV/AIDS (PLWHA) children account for approximately 13,000, and from 4800 total new infections, 880 are $<15$ years old children in this region. ${ }^{33}$

Finote-Selam General Hospital, four primary hospitals (Adet, Burie, Durbetie, and Merawi) and five health centers (Adet, Burie, Dembecha, Durbetie, and Jiga) were included in the study.

\section{Study Participants}

All HIV-infected children on ART with $>1000$ copies/mL in two consecutive viral load measurements after 3 months, enhanced support following the first viral load test were cases (virological treatment failure), while study participants with a viral load level of $\leq 1000$ copies/mL and taking first-line ART for at least six months were considered as a control. ${ }^{34}$

\section{Eligibility Criteria}

All HIV-infected children aged $<15$ years and had followup on ART from January 2016 to June 2020 with documented viral load results, were included in the study. However, children who had a follow-up $<6$ months and had not documented viral load results at the selected health institutions were excluded.

\section{Sample Size Determination and Sampling Procedure}

Sample size was determined by using Epi Info TM 7 Statcalc, unmatched case-control formula. Assumptions were 95\% confidence interval, $80 \%$ power, and 1:3 case-to-to- control ratio were used. By assuming previous studies, being male in gender and current protease inhibitor-based ART regimen was a determinant of virological treatment failure. ${ }^{14}$ The proportion of being male by gender (control exposed 48.3 and cases exposed 66.3). The calculated sample size was 344 (258 controls and 86 cases). By adding $10 \%$ of the sample, the final sample size was found to be 378 (94 cases and 276 controls). The proportional allocation was used to obtain the required sample size for each study site. Then, the cases and controls were identified using viral load result before data collection. After identifying the cases and controls, the sampling frame was the patient's medical record number. A computergenerated simple random sampling technique was used to select cases and control groups from the list sample frame. The study participants were selected through a simple random sampling technique from a viral load registration book.

\section{Study Variables}

The main outcome was virological failure. Sociodemographic characteristics of children and their caregivers (sex, age, residency, religion, caregiver relations and status, vital status of mother and father, HIV status of caregivers, and disclosure status). Laboratory and clinical characteristics (recent hemoglobin, recent CD4 count, baseline viral load test, functional and developmental status, baseline CLINICAL stage, history of TB illness, current TB status, opportunistic illness and nutritional status). HIV treatment and drug-related characteristics (duration of ART, adherence, Co-trim oxazole, and isoniazid prophylaxis use, change of regimen, current regimen, reason for regimen change) were independent variables.

\section{Operational Definitions}

Virological failure is defined as a viral load above 1000 copies/mL based on two consecutive tests within 3-months adherence support after at least 6 months on ART. ${ }^{8}$

Children: Individuals with age less than 15 years old.

Regimen change: Modification of any or all of the initial drugs.

Treatment adherence was determined using the WHO definition in the follow-up chart.

Good adherence to ART: Is a patient taking $\geq 95 \%$ of the recommended regime, fair adherence to treatment is defined as a patient taking the drug between $85 \%$ and $95 \%$ of the recommended regimen, and poor adherence to treatment is defined as a patient taking $<85 \%$ of the recommended regimen. ${ }^{35}$

\section{Data Collection Procedures and Quality Assurance}

Data were extracted by using a structured and pretested questionnaire developed from the Ethiopian National 
Comprehensive ART guidelines, available in recording and reporting formats at ART clinics. ${ }^{35}$ The tool was further customized based on the children's ART monitoring record book. Four clinical nurses who had basic ART training and working in ART clinics were data collectors. Two-day trainings on data collection or extraction techniques, and variables to be collected, were given to data collectors and supervisors. The principal investigator and two supervisors closely monitored the whole data collection process daily and gave feedback whenever needed. The data were checked for completeness, inconsistencies, and missing values before data entry.

\section{Data Processing and Analysis}

Data were entered into Epi data 4.2 and then exported to SPSS version 20 for analysis. After cleaning and editing the data by running simple frequencies and crosstabulation, descriptive statistics were computed to report the demographic and clinical characteristics of cases and controls. Bivariate analysis was performed to assess for a crude association between independent and outcome variables. For variables with a $\mathrm{P}$-value $\leq 0.25$ according to the bivariate analysis, a multivariate binary logistic regression analysis was carried out to identify independent determinants of virological failure. Model of the goodness of fit was checked by Hosmer-Lemeshow goodness-of-fit test. Multicollinearity between the independent variables was also checked. Variables that have a strong association with virological failure were identified based on odds ratios (OR) with its 95\% confidence interval (CI). A p-value $\leq 0.05$ was considered to be of statistical significance.

\section{Ethical Consideration}

Ethical clearance was obtained from the ethical review committee of College of Health science, Debre Markos University with the approval reference No: $\mathrm{HSC} / \mathrm{R} / \mathrm{C} / \mathrm{Scr} /$ $\mathrm{Co} / 113 / 11 / 13$ and a support letter no, $\mathrm{HSC} / \mathrm{R} / \mathrm{C} / \mathrm{Scr} / \mathrm{Co} /$ 114/11/13 both dated on October 24, 2020. All methods were performed in accordance with the relevant regulations and according to the criteria set by Declaration of Helsinki. Informed consent was waived by the review committee as all the data source of patients' medical record numbers was anonymously registered using codes without personal identifiers such as names of patients. Permission letters for the selected public health facilities were obtained from the West Gojjam Zonal Health Department. Permission was also secured from the respective health facilities' leaders. The data were collected by maintaining confidentiality while reviewing the card of the patient.

\section{Results}

\section{Socio-Demographic Characteristics}

During our data extraction process, from 378 HIV-infected children, medical charts', 370 were included and eight medical charts were excluded due to missed charts and incomplete data. A total of 94 cases and 276 controls were included in the study. Fifty-seven $(60.6 \%)$ of the cases and $165(59.8 \%)$ of the controls were males. The majority 73 $(77.7 \%)$ of cases and $208(75.4 \%)$ of controls were age group $\geq 10$ years. Fifty $(53.2 \%)$ of the cases and 162 $(58.7 \%)$ of the controls were living in urban areas. Seventy $(74.5 \%)$ of the cases and $226(81.9 \%)$ of the controls were living with parents (father/mother). About $70(74.5 \%)$ of cases and $223(80.8 \%)$ of controls had an HIV-positive caregiver. Sixty-five $(69.1 \%)$ of the cases and $191(69.2 \%)$ of the controls were having a mother. About $41(43.6 \%)$ of cases and $189(68.5 \%)$ of controls were disclosed about HIV status (Table 1).

\section{Laboratory and Clinical Related Characteristics}

About 48 (51.1\%) of cases and 130 (47.1\%) of controls had recent hemoglobin below $12.5 \mathrm{~g} / \mathrm{dl}$, respectively. Fiftyseven $(60.6 \%)$ of the cases and $173(62.6 \%)$ of controls had a recent CD4 count category $\geq 500$ cells $/ \mathrm{mm} 3$. About $71(75.5 \%), 14(14.9)$ of cases and 51 (18.5\%), 62 (22.5\%) of controls had baseline and recent viral load $>1000$ copies/mL respectively. According to functional status for age $\geq 5$ years, majority $84(89.4 \%)$ of cases and 253 $(91.6 \%)$ of controls were working. About nine $(9.6 \%)$ of the cases and $14(5.1 \%)$ of controls had appropriate for age and developmental status. Thirty-three (24.5\%) of cases and $75(27.2 \%)$ of controls had baseline CLINICAL stage II at ART initiation. The majority $85.1 \%$ of the cases and $97.8 \%$ of controls had negative current TB status. Twenty-eight $(29.8 \%)$ of the cases and $73(26.8 \%)$ of the controls had a history of opportunistic infections (Table 2).

\section{HIV Treatment and Drug Related Characteristics}

The majority $58(61.7 \%)$ of cases and 205 (74.3\%) of controls had $\geq 48$ months duration from the start of ART. 
Table I Socio-Demographic Characteristics of Children on First-Line ART and Their Caregivers at Public Health Facilities in the West Gojjam Zone from 2016 to 2020

\begin{tabular}{|c|c|c|c|c|}
\hline \multirow[t]{2}{*}{ Variable } & \multirow[t]{2}{*}{ Category } & Cases & Controls & Total \\
\hline & & $\mathbf{N}(\%)$ & $\mathbf{N}(\%)$ & $\mathbf{N}(\%)$ \\
\hline \multirow[t]{2}{*}{ Sex } & Male & $57(60.6)$ & $165(59.8)$ & $222(80.4)$ \\
\hline & Female & $37(39.4)$ & III(40.2) & $148(53.6)$ \\
\hline \multirow[t]{3}{*}{ Age group } & $<5$ years & $10(10.6)$ & $13(4.7)$ & $23(6.2)$ \\
\hline & $5-9$ years & $20(21.3)$ & $55(19.9)$ & $75(20.3)$ \\
\hline & $\geq 10$ years & $64(68.1)$ & $208(75.4)$ & $272(73.5)$ \\
\hline \multirow[t]{2}{*}{ Residence } & Urban & $50(53.2)$ & 162(58.7) & $212(57.3)$ \\
\hline & Rural & $44(46.8)$ & II4(4I.3) & $158(42.7)$ \\
\hline \multirow[t]{3}{*}{ Religion } & Orthodox & $75(79.8)$ & $26 I(94.5)$ & $336(90.8)$ \\
\hline & Muslim & $10(10.6)$ & $9(3.3)$ & $19(5.1)$ \\
\hline & Protestant & $9(9.6)$ & $6(2.2)$ & $15(4.1)$ \\
\hline \multirow[t]{3}{*}{ Caregiver relation } & Parents (mother/father) & $70(74.5)$ & $226(81.9)$ & $296(80.0)$ \\
\hline & Other & $16(17.0)$ & $32(11.6)$ & $48(12.9)$ \\
\hline & Orphan & $8(8.5)$ & $18(6.5)$ & $26(7.1)$ \\
\hline \multirow[t]{3}{*}{ Caregiver HIV status } & Positive & $70(74.5)$ & $223(80.8)$ & 293(79.2) \\
\hline & Negative & $12(12.8)$ & $40(14.5)$ & $52(14.1)$ \\
\hline & Unknown & $12(12.8)$ & $13(4.7)$ & $25(6.7)$ \\
\hline \multirow[t]{3}{*}{ Vital status of the mother } & Alive & $65(69.1)$ & $191(69.2)$ & $256(69.2)$ \\
\hline & Dead & $20(21.3)$ & $80(29.0)$ & $100(27.0)$ \\
\hline & Do not know & $9(9.6)$ & $5(1.8)$ & $14(3.8)$ \\
\hline \multirow[t]{3}{*}{ Vital status of the father } & Alive & $53(56.4)$ & I6I(58.3) & $214(57.8)$ \\
\hline & Dead & $3 I(32.9)$ & 108(39.1) & $139(37.6)$ \\
\hline & Do not know & $10(10.6)$ & $7(2.5)$ & $17(4.6)$ \\
\hline \multirow[t]{2}{*}{ Disclosure status } & Disclosed & $4 I(43.6)$ & $189(68.5)$ & $230(62.2)$ \\
\hline & Non disclosed & $53(56.4)$ & $87(31.5)$ & $140(37.8)$ \\
\hline
\end{tabular}

Twenty $(21.3 \%)$ of the cases and seven $(2.5 \%)$ of the controls were poor recent adherence. About 56 (59.6\%) of the cases and $28(10.1 \%)$ of controls had a history of missed clinical appointments. The Majority 70 (74.4\%) of cases and $234(84.8 \%)$ of controls had completed cotrimoxazole prophylaxis. The majority 70 (70.5\%) of cases and $253(91.7 \%)$ of controls were also provided isoniazid prophylaxis. About $43(45.7 \%)$ of cases and
114 (41.3\%) of controls were LPV/R based on the regimen. Seventy-five (79.8\%) of cases and 232 (84.1\%) of controls had a history of ARV drug change (Table 3 ).

\section{Virological Treatment Failure}

In this study, the overall prevalence of virological failure within the first versus third monthly visit was found to be 102 (27.6) and 76 (20.5\%), respectively. 
Table 2 Laboratory and Clinical Related Informations Among HIV-Infected Children at Public Health Facilities in West Gojjam Zone, Amhara Region, Ethiopia, 2020

\begin{tabular}{|c|c|c|c|}
\hline \multirow[t]{2}{*}{ Variable } & \multirow[t]{2}{*}{ Category } & Cases & Controls \\
\hline & & $\mathbf{N}(\%)$ & $\mathbf{N}(\%)$ \\
\hline \multirow[t]{2}{*}{ Recent hemoglobin } & $<12.5 \mathrm{~g} / \mathrm{dl}$ & $48(51.1)$ & $130(47.1)$ \\
\hline & $\geq 12.5 \mathrm{~g} / \mathrm{dl}$ & $46(48.9)$ & $146(52.9)$ \\
\hline \multirow[t]{3}{*}{ Recent CD4 } & $<250$ cells $/ \mathrm{mm} 3$ & $15(15.9)$ & $57(20.6)$ \\
\hline & $250-500$ cells $/ \mathrm{mm} 3$ & $22(23.4)$ & $46(16.6)$ \\
\hline & $\geq 500$ cells $/ \mathrm{mm} 3$ & $57(60.6)$ & $173(62.6)$ \\
\hline \multirow[t]{2}{*}{ Baseline viral load result } & $\leq 1000$ copies $/ \mathrm{mL}$ & $23(24.5)$ & $225(81.5)$ \\
\hline & $>1000$ copies $/ \mathrm{mL}$ & $7 I(75.5)$ & $5 I(18.5)$ \\
\hline \multirow[t]{2}{*}{ Recent viral load result } & $\leq 1000$ copies $/ \mathrm{mL}$ & $80(85.1)$ & $2 \mid 4(77.5)$ \\
\hline & $>1000$ copies $/ \mathrm{mL}$ & I4(I4.9) & $62(22.5)$ \\
\hline \multirow[t]{2}{*}{ Functional status for age $\geq 5$ years } & Working & $84(89.4)$ & $253(91.6)$ \\
\hline & Ambulatory and bed ridding & $10(10.6)$ & $13(4.7)$ \\
\hline \multirow[t]{2}{*}{ Developmental status for age $<5$ years } & Appropriate for the age & $9(9.6)$ & $14(5.1)$ \\
\hline & Delay and regression & $85(90.4)$ & $262(94.9)$ \\
\hline \multirow[t]{3}{*}{ Baseline WHO clinical stage } & Stage I & $32(34.0)$ & $138(50)$ \\
\hline & Stage II & $23(24.5)$ & $75(27.2)$ \\
\hline & Stage III \& IV & $39(4 \mid .5)$ & $63(22.8)$ \\
\hline \multirow[t]{2}{*}{ Current TB status } & Positive & I4(I4.9) & $6(2.2)$ \\
\hline & Negative & $80(85.1)$ & $270(97.8)$ \\
\hline \multirow[t]{2}{*}{ Opportunistic infections } & Yes & $28(29.8)$ & $73(26.4)$ \\
\hline & No & $66(70.2)$ & $203(73.6)$ \\
\hline \multirow[t]{4}{*}{ Nutritional status of children } & Severe Acute Malnutrition & $9(9.6)$ & $3(10.8)$ \\
\hline & Moderate Acute Malnutrition & $54(57.4)$ & $84(30.4)$ \\
\hline & Mild malnutrition & $24(25.5)$ & $49(17.8)$ \\
\hline & Normal & $7(74.5)$ & $140(50.0)$ \\
\hline
\end{tabular}

\section{Factors Associated with ART Virological} Failure

The bivariate logistic regression analysis showed that nondisclosure of HIV status, baseline viral load $>1000$ copies/ $\mathrm{mL}$, WHO clinical stage, recent adherence, and missed clinical appointment were associated with virological failure.

After adjustment for possible effects of confounding variables non-disclosure $(\mathrm{AOR}=4.26 ; 95 \% \mathrm{CI}: 2.09$, 8.70), baseline viral load $>1000$ copies $/ \mathrm{mL}$ (AOR =
10.82; 95\% CI: 5.4, 21.67), recent poor adherence (AOR, $6.05,95 \% \mathrm{CI}, 1.70,21.55)$ and missed clinical appointments (AOR $=8.03$; 95\% CI: 3.88, 16.65) were found to be significantly associated factors with virological failure (Table 4).

\section{Discussion}

As described above, the prevalence of virological failure decreased from baseline to recent viral load results might 
Table 3 HIV Treatment and Drug-Related Characteristics Among HIV-Infected Children at Public Health Facilities in West Gojjam Zone, Amhara Region, Ethiopia, 2020

\begin{tabular}{|c|c|c|c|}
\hline \multirow[t]{2}{*}{ Variable } & \multirow[t]{2}{*}{ Category } & Cases & Controls \\
\hline & & $\mathbf{N}(\%)$ & $\mathbf{N}(\%)$ \\
\hline \multirow[t]{3}{*}{ Duration on ART } & $\leq 14$ months & $15(15.9)$ & $7(2.5)$ \\
\hline & I5-47 months & $2 \mathrm{I}(22.3)$ & $64(23.2)$ \\
\hline & $\geq 48$ months & $58(61.7)$ & $205(74.3)$ \\
\hline \multirow[t]{3}{*}{ Recent adherence } & Good (>95\%) & $67(7 \mid .2)$ & $264(95.7)$ \\
\hline & Fair (85-95\%) & $7(7.5)$ & $5(1.8)$ \\
\hline & Poor (<85\%) & $20(21.3)$ & $7(2.5)$ \\
\hline \multirow[t]{2}{*}{ Missed clinical appointment } & Yes & $56(59.6)$ & $28(10.1)$ \\
\hline & No & $38(40.4)$ & $248(89.9)$ \\
\hline \multirow[t]{2}{*}{ Co-trimoxazole prophylaxis use } & Completed & $70(74.5)$ & $234(84.8)$ \\
\hline & Not completed & $24(25.5 \%)$ & $42(15.2)$ \\
\hline \multirow[t]{2}{*}{ Isoniazid prophylaxis use } & Completed & $70(74.5)$ & $253(91.7)$ \\
\hline & Not completed & $24(25.5 \%)$ & $23(8.3)$ \\
\hline \multirow[t]{2}{*}{ History of ARV drug change } & Yes & $75(79.8)$ & $232(84.1)$ \\
\hline & No & $19(20.2)$ & $44(15.9)$ \\
\hline \multirow[t]{3}{*}{ Current regimen } & NVP based & $19(20.2)$ & $61(22.1)$ \\
\hline & EFV based & $32(34.1)$ & $101(36.6)$ \\
\hline & LPV/R based & $43(45.7)$ & $\mid I 4(4 \mid .3)$ \\
\hline \multirow[t]{2}{*}{ Reason for $A R V$ regimen change } & Drug side effect & $25(26.6)$ & $88(31.9)$ \\
\hline & New drug availability & $69(73.4)$ & $188(68.1)$ \\
\hline
\end{tabular}

Abbreviations: BMl, body mass index; b/n, between.

be due to an appropriate drug adherence follow-up and counseling supports including other ART management services provided to HIV infected children over time.

Our findings revealed that the odds value of virological failure among HIV-infected children with non-disclosure was 4.26 times more compared to those children with disclosed HIV status. This result was consistent with other studies done in Tanzania ${ }^{17}$ which revealed that full disclosure of HIV status for children was associated with a protective effect against virological failure and Dodoma municipal $^{22}$ which showed that non-disclosed children were 7.74 times more likely to have virological failure than those compared with those disclosed. The result is also in line with the study conducted in Ethiopia ${ }^{15,19}$ which showed for a checkup that disclosure of HIV status was found to be preventive to virological failure. This could be the fact that non-disclosure increases the sense of anxiety, difficulty of taking off their treatment on time and results in reduced drug effectiveness among children.

This study found that the likelihood of developing virological treatment failure in children who had a baseline viral load results $>1000$ copies $/ \mathrm{mL}$ was 10.82 times more likely to develop virological treatment failure than those children who had baseline viral load results in $\leq 1000$ copies $/ \mathrm{mL}$. This study was in line with the study done in Swaziland, ${ }^{27}$ Uganda. ${ }^{21}$ This might be because children have limited evidence of viral load monitoring, which leads to poor adherence and reduced immunity.

In this study, children who had a history of poor adherence were 6.05 times more likely to develop virological 
Table 4 Determinants of Virological Failure Among HIV-Infected Children in West Gojjam Zone at Public Health Facilities, 2020

\begin{tabular}{|c|c|c|c|c|c|}
\hline \multirow[t]{2}{*}{ Variable } & \multirow[t]{2}{*}{ Category } & \multirow{2}{*}{$\begin{array}{l}\text { Cases } \\
(\mathbf{N})\end{array}$} & \multirow{2}{*}{$\begin{array}{l}\text { Controls } \\
(\mathrm{N})\end{array}$} & \multirow[t]{2}{*}{ COR $(95 \% \mathrm{Cl})$} & \multirow[t]{2}{*}{ AOR $(95 \% \mathrm{Cl})$} \\
\hline & & & & & \\
\hline \multirow[t]{2}{*}{ HIV status disclosure } & Disclosed & 41 & 189 & 1 & I \\
\hline & Not disclosed & 53 & 87 & $2.81(1.74,4.54)$ & $4.26(2.09,8.70)^{*}$ \\
\hline \multirow[t]{2}{*}{ Baseline viral load } & $\leq 1000$ copies $/ \mathrm{mL}$ & 23 & 225 & 1 & I \\
\hline & $>1000$ copies $/ \mathrm{mL}$ & 71 & 51 & I $3.62(7.78,23.84)$ & $10.82(5.40,21.67)^{*}$ \\
\hline \multirow[t]{3}{*}{ WHO clinical stage } & Stage I & 32 & 138 & 1 & I \\
\hline & Stage II & 23 & 75 & I.322 $(0.722,2.422)$ & I.78 $(0.74,4.27)$ \\
\hline & Stage III\&IV & 39 & 63 & $2.58(1.47,4.55)$ & $2.19(0.98,4.91)$ \\
\hline \multirow[t]{3}{*}{ Recent adherence } & Good & 73 & 264 & 1 & I \\
\hline & Fair & 1 & 5 & $0.72(0.10,6.29)$ & $1.12(0.03,39.28)$ \\
\hline & Poor & 20 & 7 & $10.33(4.21,25.39)$ & $6.05(1.70,21.55)^{*}$ \\
\hline \multirow[t]{2}{*}{ Missed clinical appointment } & Yes & 56 & 28 & I3.05 (7.4,23.03) & $8.03(3.88,16.61)^{*}$ \\
\hline & No & 38 & 248 & I & I \\
\hline
\end{tabular}

Notes: *Statistically significant at $\mathrm{p}$-value $<0.05$ : I, is a constant use as a comparison.

treatment failure than those children who had a history of good adherence. The result was comparable to a study done in Thailand ${ }^{36}$ which showed that poor adherence increases the odds value of virological failure and Malawi ${ }^{21}$ which revealed that a high percentage of virological failure was due to poor adherence. The study was also in line with the study done in Dodoma municipal, ${ }^{22}$ Tanzania, ${ }^{32}$ and Senegal, ${ }^{13}$ Wollo. ${ }^{37}$ This might be due to poor adherence causing periodic viral replication that result in the development of drug resistance and limited treatment outcomes.

In the present study, those children with a history of missed clinical appointments were 8.03 times more likely to develop virological treatment failure than those with no history of missed clinical appointment. The result is in line with the study done in Senegal ${ }^{13}$ which showed that prolonged antiretroviral interruption was more likely to develop virological treatment failure 2.7 times when compared with no history of drug interruption. This might be because missed clinical appointment leads to missing their dose, resulting in poor adherence.

\section{Limitations of the Study}

In this study, since we used existing routinely recorded facility data, either we failed to capture some important variables due to missing records or the variables may not be required for patient care purposes. There were problems in selecting an appropriate control for the study participants. It was only possible to establish an association between virological failure and the risk factors, as it was not known what occurred first. That is, cause and effect relationships were not addressed in this study.

\section{Conclusion}

The determinants for virological treatment failure were nondisclosure of HIV status, baseline viral load $>1000$ copies $/ \mathrm{mL}$, poor adherence, and missing clinical appointment. Health workers should pay attention to disclose patients early according to their age, give strict adherence counseling, and fast trace back those who miss their clinical appointment, strictly follow for those with baseline viral loads $>1000$ copies $/ \mathrm{mL}$, and provide evidence for their clients about lab results.

Patients should take their medication as prescribed and consult their clinician when needed. Program leaders should monitor and evaluate the recording systems and improve health information system. Research studies focused on patient quality of care with HIV should be emphasized for the future.

\section{Acknowledgment}

The authors would like to thank the academic staff of Debre Markos University, College of Health Science, for the support and selection of the topic. The authors would 
also like to thank health institutions providing ART services under West Gojjam Zonal Health Department. In addition, the authors' deep thanks goes to health professionals working at ART center, data collectors, and supervisors for giving them the chance to conduct this study.

\section{Author Contributions}

All authors made a significant contribution to the work reported, whether that is in the conception, study design, execution, acquisition of data, analysis and interpretation, or in all these areas; took part in drafting, revising or critically reviewing the article; gave final approval of the version to be published; have agreed on the journal to which the article has been submitted; and agree to be accountable for all aspects of the work.

\section{Disclosure}

The authors report no conflicts of interest in this work.

\section{References}

1. Joint United Nations Programme on HIV and AIDS. Global HIV \& AIDS statistics - fact sheet; 2021. Available from: https://www. unaids.org/en/resources/fact-sheet. Accessed October 6, 2021.

2. Joint United Nations Programme on AIDS. UNAIDS Global AIDS Update; July 14, 2021:2021.

3. World Health Organization. Latest HIV Estimates and Updates on HIV Policies Uptake; July, 2021:2021.

4. UNAIDS. 2025 AIDS TARGETS; 2020. Available from: https://www. unaids.org/sites/default/files/2025-AIDS-Targets_en.pdf. Accessed December 10, 2021.

5. HIV/AIDS JUNPo, HIV/Aids JUNPo. 90-90-90: An Ambitious Treatment Target to Help End the AIDS Epidemic. Geneva: Unaids; 2014.

6. Global data on HIV epidemiology and response; 2020. Available from: https://aidsinfo.unaids.org/. Accessed October 9.

7. Agency ECs. Ethiopia Demographic and Health Survey 2016: HIV Report. Addis Ababa, Ethiopia, and Rockville, Maryland, USA: CSA and ICF; 2016

8. Organization WH. Consolidated Guidelines on the Use of Antiretroviral Drugs for Treating and Preventing HIV Infection: Recommendations for a Public Health Approach. World Health Organization; 2016.

9. Infection PoCPfToH. Guidelines for the use of antiretroviral agents in HIV-infected adults and adolescents. Afr J Med Pract. 1998;5(2):79.

10. Maartens G, Celum C, Lewin SR. HIV infection: epidemiology, pathogenesis, treatment, and prevention. Lancet. 2014;384 (9939):258-271. doi:10.1016/S0140-6736(14)60164-1

11. Arpadi SM, Shiau S, De Gusmao EP, Violari A. Routine viral load monitoring in HIV-infected infants and children in low-and middle-income countries: challenges and opportunities. $J$ Int AIDS Soc. 2017;20:e25001. doi:10.1002/jia2.25001

12. Zoufaly A, Fillekes Q, Hammerl R, et al. Prevalence and determinants of virological failure in HIV-infected children on antiretroviral therapy in rural Cameroon: a cross-sectional study. Antivir Ther. 2013;18(5):681-690. doi:10.3851/IMP2562

13. Cissé A-M, Laborde-Balen G, Kébé-Fall K, et al. High level of treatment failure and drug resistance to first-line antiretroviral therapies among HIV-infected children receiving decentralized care in Senegal. BMC Pediatr. 2019;19(1):47. doi:10.1186/s12887-019$1420-z$
14. Kadima J, Patterson E, Mburu M, et al. Adoption of routine virologic testing and predictors of virologic failure among HIV-infected children on antiretroviral treatment in western Kenya. PLoS One. 2018;13(11):e0200242. doi:10.1371/journal.pone.0200242

15. Misganie YG, Yizengaw A, Likie A, et al. Rate and predictors of treatment failure among pediatric population taking highly active antiretroviral therapy in Ethiopia. medRxiv. 2019;19005538.

16. Bacha T, Tilahun B, Worku A. Predictors of treatment failure and time to detection and switching in HIV-infected Ethiopian children receiving first line anti-retroviral therapy. BMC Infect Dis. 2012;12 (1):197. doi:10.1186/1471-2334-12-197

17. Emmett SD, Cunningham CK, Mmbaga BT, et al. Predicting virologic failure among HIV-1-infected children receiving antiretroviral therapy in Tanzania: a cross-sectional study. J Acquir Immune Defic Syndr. 2010;54(4):368. doi:10.1097/QAI.0b013e3181cf4882

18. Barry O, Powell J, Renner L, et al. Effectiveness of first-line antiretroviral therapy and correlates of longitudinal changes in CD4 and viral load among HIV-infected children in Ghana. BMC Infect Dis. 2013;13(1):476. doi:10.1186/1471-2334-13-476

19. Sisay MM, Ayele TA, Gelaw YA, Tsegaye AT, Gelaye KA, Melak MF. Incidence and risk factors of first-line antiretroviral treatment failure among human immunodeficiency virus-infected children in Amhara regional state, Ethiopia: a retrospective follow-up study. BMJ Open. 2018;8(4):e019181. doi:10.1136/bmjopen-2017-019181

20. Bienczak A, Denti P, Cook A, et al. Plasma efavirenz exposure, sex, and age predict virological response in HIV-infected African children. $J$ Acquir Immune Defic Syndr. 2016;73(2):161. doi:10.1097/QAI.0000000000001032

21. Kityo C, Boerma RS, Sigaloff KC, et al. Pretreatment HIV drug resistance results in virological failure and accumulation of additional resistance mutations in Ugandan children. $J$ Antimicrob Chemother. 2017;72(9):2587-2595. doi:10.1093/jac/dkx188

22. Bitwale NZ, Mnzava DP, Kimaro FD, Jacob T, Mpondo BC, Jumanne S. Prevalence and factors associated with virological treatment failure among children and adolescents on antiretroviral therapy attending HIV/AIDS care and treatment clinics in Dodoma municipality, central Tanzania. J Pediatric Infect Dis Soc. 2021;10 (2):131-140.

23. EPHI P. ICAP. Ethiopia Population-Based HIV Impact Assessment Ephia 2017-2018. Summary Sheet: Preliminary Findings; 2018.

24. Osman FT, Yizengaw MA. Virological failure and associated risk factors among HIV/AIDS pediatric patients at the ART clinic of Jimma University Medical Center, Southwest Ethiopia. Open AIDS J. 2020;14(1):61-67. doi:10.2174/1874613602014010061

25. Barennes H, Virak K, Rouet F, Buisson Y, Strobel M, Vibol U. Factors associated with the failure of first and second-line antiretroviral therapies therapy, a case control study in Cambodian HIV-1 infected children. BMC Res Notes. 2016;9(1):69. doi:10.1186/ s13104-016-1884-y

26. Mehta K, Ekstrand M, Heylen E, Sanjeeva G, Shet A. Adherence to antiretroviral therapy among children living with HIV in South India. AIDS Behav. 2016;20(5):1076-1083. doi:10.1007/s10461015-1207-7

27. Jobanputra K, Parker LA, Azih C, et al. Factors associated with virological failure and suppression after enhanced adherence counselling, in children, adolescents and adults on antiretroviral therapy for HIV in Swaziland. PLoS One. 2015;10(2):e0116144. doi:10.1371/ journal.pone. 0116144

28. Njom Nlend AE, Motaze AN, Ndiang ST, Fokam J. Predictors of virologic failure on first-line antiretroviral therapy among children in a referral pediatric center in Cameroon. Pediatr Infect Dis J. 2017;36 (11):1067-1072. doi:10.1097/INF.0000000000001672

29. Shiferaw MB, Endalamaw D, Hussien M, et al. Viral suppression rate among children tested for HIV viral load at the Amhara public health institute, Bahir Dar, Ethiopia. BMC Infect Dis. 2019;19(1):1-6. doi:10.1186/s12879-019-4058-4 
30. Kamya MR, Mayanja-Kizza H, Kambugu A, et al. Predictors of long-term viral failure among Ugandan children and adults treated with antiretroviral therapy. J Acquir Immune Defic Syndr. 2007;46 (2):187-193. doi:10.1097/QAI.0b013e31814278c0

31. Mensah E. Predictors of Virological Failure Among Children Infected with HIV-1 on Haart at KATH. 2017. Available from: http://ir.knust. edu.gh:8080/handle/123456789/10001. Accessed February 4, 2019.

32. Muri L, Gamell A, Ntamatungiro AJ, et al. Development of HIV drug resistance and therapeutic failure in children and adolescents in rural Tanzania: an emerging public health concern. AIDS. 2017;31(1):61. doi:10.1097/QAD.0000000000001273

33. ARHB. EFY 2013 Eight Month HIV Prevention \& Control Program Performance Review. Debre Tabor: ARHB; 2021.
34. WHO. Guideline on When to Start Antiretroviral Therapy and on Pre-Exposure Prophylaxis for HIV. Switzerland: WHO; 2015.

35. Minstery of Health E. National Consolidated Guidelines for Comprehensive HIV Prevention, Care and Treatment. Addis Ababa: $\mathrm{MoH} ; 2018$.

36. Moolasart V, Chottanapund S, Ausavapipit J, et al. The effect of detectable HIV viral load among HIV-infected children during antiretroviral treatment: a cross-sectional study. Children. 2018;5(1):6. doi:10.3390/children5010006

37. Seid A, Cherie N, Ahmed K. Determinants of virologic failure among adults on second line antiretroviral therapy in Wollo, Amhara Regional State, Northeast Ethiopia. HIV/AIDS. 2020;12:697.

\section{Publish your work in this journal}

HIV/AIDS - Research and Palliative Care is an international, peerreviewed open-access journal focusing on advances in research in HIV, its clinical progression and management options including antiviral treatment, palliative care and public healthcare policies to control viral spread. The manuscript management system is completely online and includes a very quick and fair peer-review system, which is all easy to use. Visit http://www.dovepress.com/testimonials.php to read real quotes from published authors. 